\title{
THE USE OF NEW TECHNOLOGIES IN THE RESTORATION AND CONSERVATION OF BUILT CULTURAL HERITAGE/ THE CASE OF THE STATUE OF FOUARA, SETIF, ALGERIA
}

\author{
N. Ali Khodja, H. Zeghlache*, F. Benali, O. Guani \\ Laboratoire d'Architecture Mediterranenenne, Universite Ferhat Abbas, Setif, Algeria - \\ alikhodja.nadir@univ-setif.dz, ,zeghlach@yahoo.fr, benalifarouk@univ-setif.dz,o_gueni@yahoo.fr
}

Commission VI, WG VI/4

KEY WORDS: Cultural Heritage, digitization, restoration, Algeria, laser Scanning

\begin{abstract}
:
The present paper deals with the techniques using the laser scanner survey in the restoration of the statue of Fouara in Setif, Algeria. This statue which is made of marble was realized by Francis de St Vidal in 1899 that represents a nymph which is a part of the fountain, publicly displayed in the center of the city's main plaza. On 18 December 2018, a man defaced the statue, removing the facial features and breasts with a hammer and chisel.

As a matter of fact, the build cultural heritage in Algeria is in danger from attacks and reaction time deterioration with age.

Following the day of the incident, our team has been called to use a previous scanner laser survey of the nymph that was stored in our cultural heritage monument database in order to help the restoration of the missing part of the nymph (the face and the breast. as matter of fact, the original laser scanning survey provided a helpful and accurate details to support the restoration of the nymph.
\end{abstract}

\section{INTRODUCTION}

\subsection{Cultural heritage and preservation}

Heritage built during its existence is exposed to many external threats (destruction, alterations, vandalism ...) and internal (war, conflict, degradation, insalubrities ...). This non-renewable and invaluable resource must be the subject of serious documentation and archiving. Digitization is currently a technology that has become essential for increased visibility and protection of the built heritage footprint.

The LIDAR (light detection and ranging also called laser scan) object of this article is a technique of Lasergrammetry that allows the digitization of built cultural heritage (Raimondi, 2015a). It is a data acquisition process in point cloud aspect, then in the form of 3D modeling. The massive data techniques is becoming, ore important in the conservation of cultural heritage; in recent years, such as the Terrestrial Laser Scanning (TLS); raises the possibility of developing new assessment procedures of architectural heritage. The $3 \mathrm{M}$ models that it is able to obtain are a great potential tool, both for conservation purposes and historical and architectural studies. (Costa-jover et al., 2019). The case studied is the statue of the fountain of Ain Fouara in Setif, in Algeria, which is made of marble was realized by Francis de St Vidal in 1899 that represents a nymph which is a part of the fountain, publicly displayed in the center of the city's main plaza. The Ain El Fouara fountain a symbolic statue in the town was literally cut at the level of the face and the chest by a individual, standing on this fountain breaking with a hammer and chisel the face and chest of the statue.

Actually we used the (TLS) technique for a reconstruction and an expertise of the model of the statue of the Fountain and thus show all the interest of this technology not only in the digital archiving of 3D models generated and the way that we use.
But also all the possibilities of use of these models in the study of the mechanical behaviors and studies of the construction of the patrimonial objects.

According to the new development of the technologies; the former way of operating the survey has been replaced by a digital process of modeling (Varady,1997a). However these new technologies has gave us architects an opportunity such as the automatic orientation as well as measuring process based on the new generation of 3D data on cloud points and it is applied to the digital modeling surfaces and the Web representation of the built cultural heritage (Author_x, 20xx). All these actions were used in the digital expertise on object that which undergo or undergoing deteriorations.

The workflow based on Laser Scanning in Cultural Heritage has three steps (Pesci, 2012a) in order to initialize the digitalization work.

1. The first step is acquiring the $3 \mathrm{M}$ data by the use of the laser scanner $3 \mathrm{M}$ restitution of the surfaces of the object through many stations.

2. The second step is the $3 \mathrm{D}$ modelization through engineering software for the data processing of the cloud points of the object. This step is based on the transformation of the data and the 3D geometry restitution of the object.

3. The last step is the representation based on the process of digitalization to integrate the 3D Data and other multimedia such as text, image..., in order to visualize and the specific use of the rendering of the model. 


\section{FIRST METHOD}

The process is based on the digitization of the object and then to generate a digital, model by the use of the scanner laser and the software that goes with. However, the digital model of the object is made of a $3 \mathrm{M}$ data (cloud points). The cloud points cannot be used in the $3 \mathrm{M}$ application, they should be converted into a model with the mesh triangles, NURBS or CAO model surface models by noosing the reverse engineering. The technics of conversion of the cloud points into a polygonal mesh include the triangulation and recent technics. The application such as Rapidform $(\odot$ ou Geomagic $(\odot)$ is used in the processing of the cloud points in order to use them as a format in other applications. In these applications the cloud points are used in the industrial metrology. This process is based on checking the alignment of an object with a CAO model or another cloud points and do the comparison in order to check the gap or differences between the two. These differences will be displayed in a form of a code of colors with a visual indication code showing the gap and differences between the scanned object and the CAO model .The geometrical measuring and the tolerances can be extracted directly from cloud points.

\subsection{Models Alignment:}

To align consists on superposing two cloud points in which the first one is considered as a reference and the second as an element to be compared. This step is made to verify the concordance of the two models. To align means that the two cloud points to be compared or inspected are in the same system of coordinates.

\subsection{Comparison inspection technique:}

The software of comparison or inspection, provide us three modes of alignment;

- Alignment by references

- $\quad$ Alignment RPS (Reference, Point, System)

- $\quad$ Alignment Best Fit

2.1.1 Alignment by reference: This technic uses a series of layouts, axis, points or other geometrical entities which will be adapted or associated in order to make an alignment. This technic is usually used in mechanical.

2.1.2 Alignment RPS: This technic is used to constrain some elements of the two models in particular directions in order to simulate a real fixation.

2.1.3 Alignment Best Fit: The software calculates automatically the best adjustment between the two models, it is very suitable for organic of free forms.

In our case we used the Best Fit. The alignment process took 1 to 2 minutes. After words, we made the $3 \mathrm{M}$ comparison with the color codes.
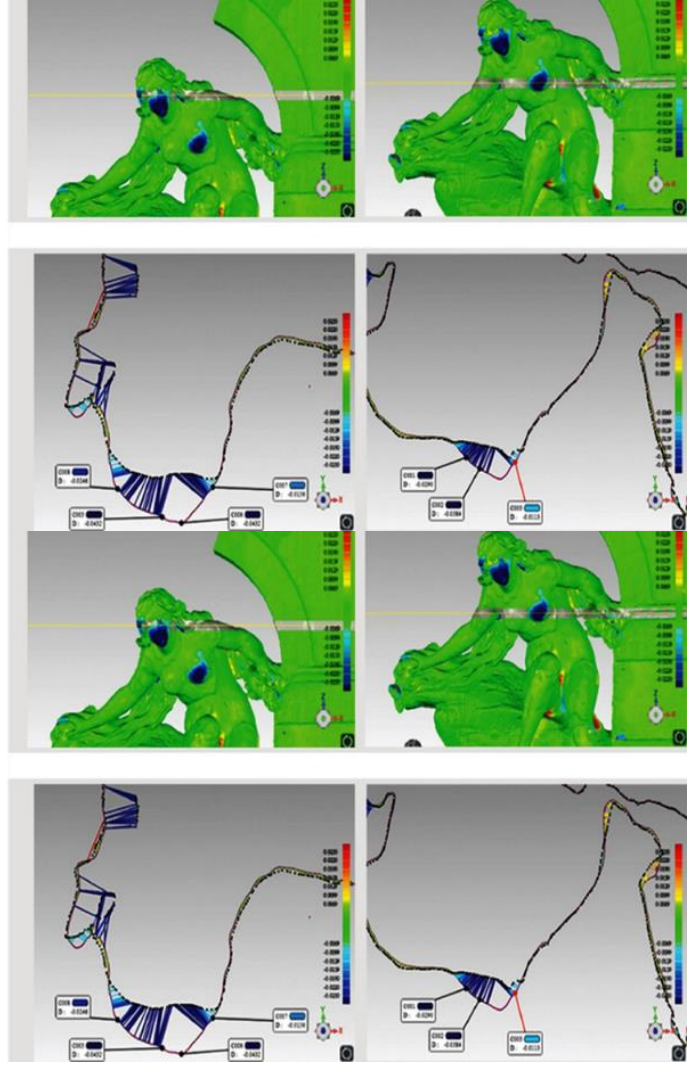

Figure1. The green zones represent a small deviation between the reference object and the test object. However, the parts of cyan or blue show a very important deviation between the two models.

This technique is very profitable for use in a digital restoration process with printed and machined parts. Indeed, with color codes, we can isolate the missing parts and make them stand out. These missing or altered parts can be replaced by composite materials in the form of synthetic resin.

\section{THE SECOND METHOD BY SECTION}

The second technic that has been used is based on the comparative study of the side section by focusing on the deterioration parts of the object.

\subsection{The first step of the workflow:}

The first work is shifting the textured object from the state 1 to the state 2. This step is very important because the good accuracy of the result depends on it. By shifting the two states of the object we obtain the fusion of the two as the third state. 


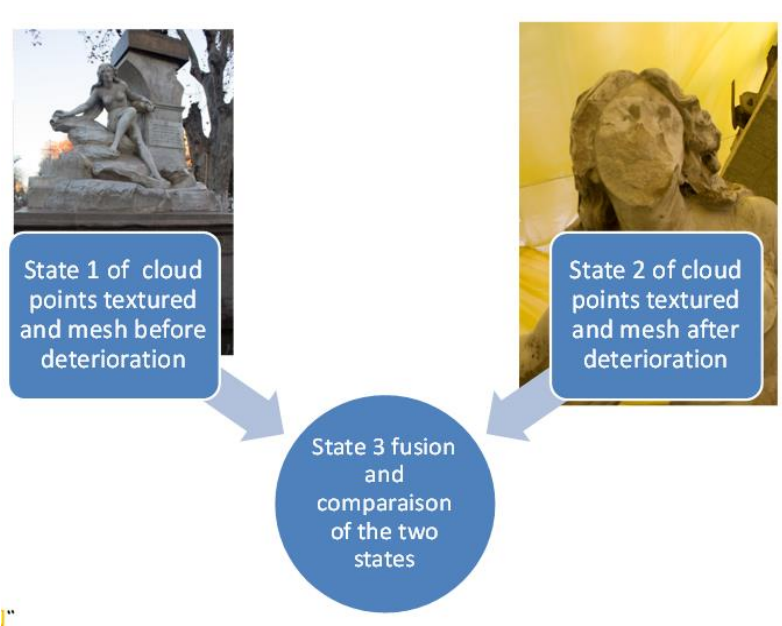

Figure 2. Process of merging pre and post incident situations.

\subsection{Choosing sections control:}

The second step of the workflow is to choose the geometry $2 \mathrm{D}$ control sections within the three axis $(\mathrm{X}, \mathrm{Y}, \mathrm{Z})$ by putting a plan section on the cloud points.

This work this depends, of course, on the nature of the heritage object being processed, but also on the precision required, particularly for the restoration operation. It is also possible to extract 2D section geometry from a point cloud, by a section plane object, except that in this case the edge accuracy and contour accuracy is not useful for a restoration work.

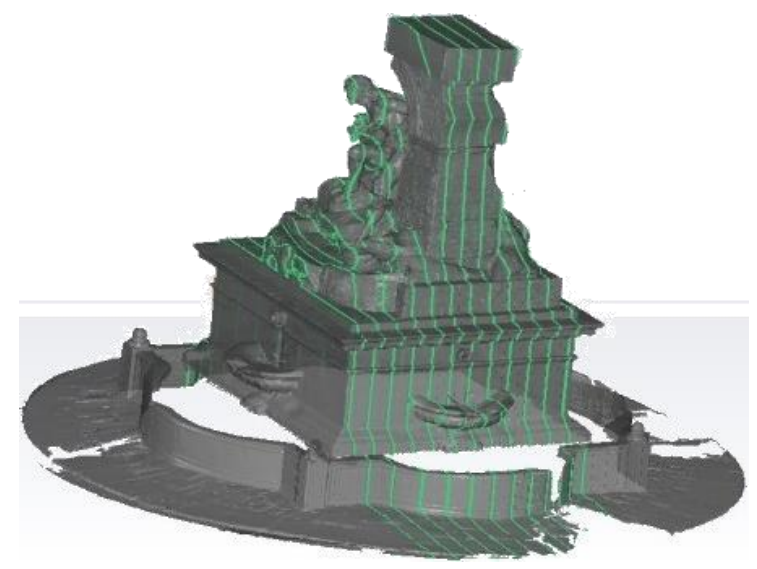

Figure 3. Sections following the $\mathrm{Z}$ axis

\subsection{Merging 2D representation:}

Third step, once the $2 \mathrm{~d}$ geometry of section plan have been done on the object: the next step would be to isolate them in order to use theme within a 2D representation CAD (Computer Aid Design) then after the section will be distinguishably colored in order to merge them with each other .

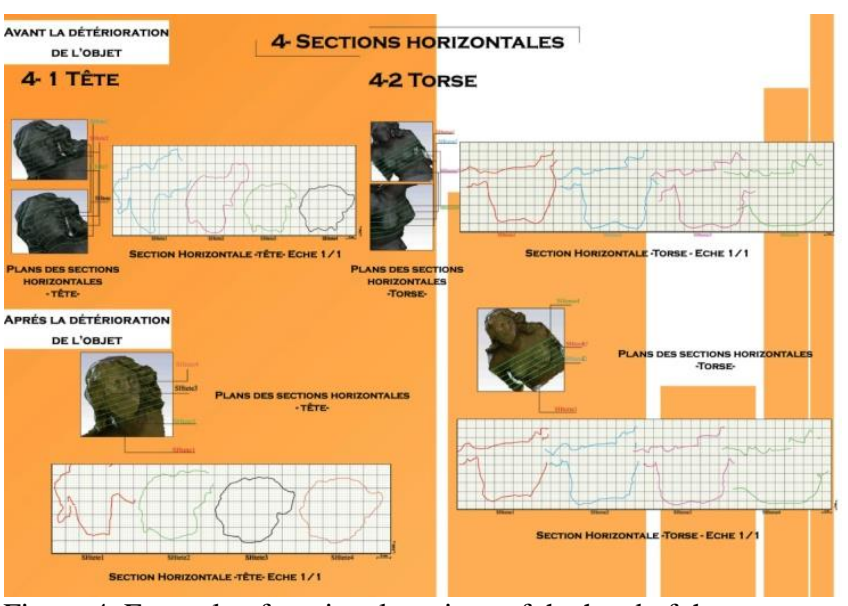

Figure 4. Example of sectional sections of the head of the statue

\subsection{Distinguishing gaps:}

At this step we can distinguish the gaps between the 2D situation 1 and situation 2 within the predefined axis XYZ.

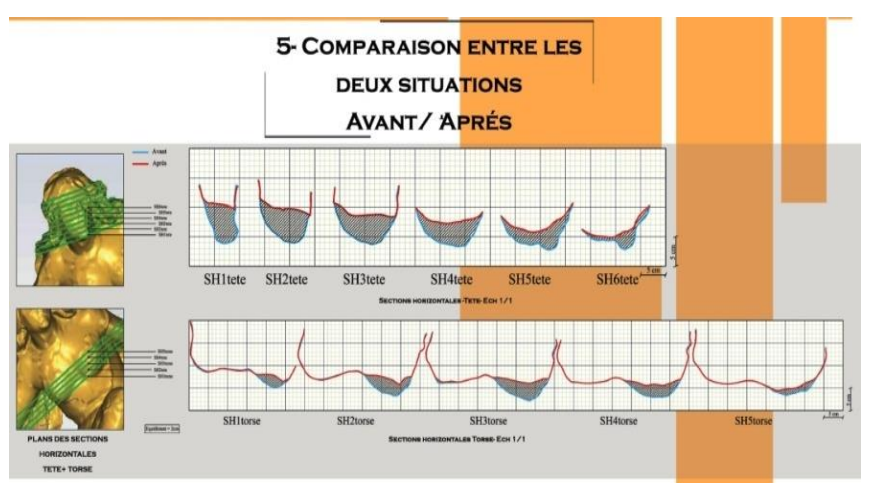

Figure 5. Some results of deterioration of the head and chest of the statue.

This second method using the sections is useful during a restoration by professionals using manual techniques. The altered parts should come out in sections with the angles and dimensions necessary for these careful and very precise operations to restore the object to its original state

\section{CONCLUSION}

On conclusion, the procedure tested has allowed to detect the degradations of the statue, especially with regard to the head and the chest (which were visible and now are accurately quantified) and formal deviations. Further research will focus on automation of procedures and testing of other useful data can be obtained from TLS for diagnosis.

The digital archiving of the built heritage includes several phases of preservation and organization. But beyond archiving and maintaining a digital model 3D laser scanning technology evolves in the most diverse fields, an increasing number of cultural institutions are taking into account the need to capture heritage sets of 3D data. These techniques are very useful in historical constructions, since the architecture is complex and irregular. despite the fact that the scanning procedures with 3D laser scanning are very heterogeneous and complex, including 
not only the economic management and logistical activities that take place in computer labs, this technology is currently an open door to the specialists who work on all forms of tangible cultural heritage, the development of computerized data systems for processing, documenting and archiving heritage is an important task, but is not an end in itself, the subsequent task is the judicious use of the fruits of that heritage.

\section{REFERENCES}

Costa-Jover et al., Terresterial Lasqer Scanner and Fast Characterization of Superficial Lesions in Architectural Diagnosis, The International Archives of the Photogrammetry, Remote Sensing and Spatial Information Sciences, Volume XLII-2/W9, 2019

Pesci, A., Bonali, E., Galli, C., Boschi, E., 2012. Laser scanning and digital imaging for the investigation of an ancient building:Palazzo d'Accursio study case (Bologna, Italy). Journal of Cultural Heritage (13), pp. 215-220.

Raimondi, V., Palombi, L., Morelli, A., Chimenti, M., Penoni, S., Dercks, U., ... \&Bracci, S. (2015, October). An integrated multi-medial approach to cultural heritage conservation and documentation: from remotely-sensed lidar imaging to historical archive data. Earth Resources and Environmental Remote Sensing/GIS Applications VI (Vol. 9644, p. 96440C). International Society for Optics and Photonics. doi: 10.1117/12.2195737.

Varady, T., Martin, R. R., \& Cox, J. (1997). Reverse engineering of geometric models - an introduction. Computer-aided design, 29(4), 255-268. doi:10.1016/S0010-4485(96)00054-1 